\title{
o-Bond Metathesis Reactions Involving Palladium(II) Hydride and Methyl Complexes: A Theoretical Assessment
}

\author{
Anne Milet, ${ }^{\dagger}$ Alain Dedieu, ${ }^{*}, \dagger$ Gerard Kapteijn,, and G. van Koten \\ Laboratoire de Chimie Quantique, UPR 139 du CNRS, Université Louis Pasteur, 4 rue Blaise Pascal, \\ F-67000 Strasbourg, France, and Debye Institute, Department of Metal-Mediated Synthesis, \\ Utrecht University, Padualaan 8, 3584CH Utrecht, The Netherlands
}

Received July 10, $1996^{\otimes}$

\begin{abstract}
$\sigma$-Bond metathesis reactions of water and methanol with palladium hydride and methyl complexes to yield hydrogen and methane, respectively, have been studied using ab-initio molecular orbital methods at the second-order Møller-Plesset (MP2) perturbation level. The calculations show that such reactions are feasible and that they can in some instances be competitive with an oxidative addition/reductive elimination sequence. A key factor is the presence of an additional lone pair not engaged in the initial bonding of the metal atom with the reacting water or alcohol. Another important controlling factor is the respective charges of the reacting entities. The importance of the choice and of the disposition of the ancillary ligands in the coordination sphere is emphasized.
\end{abstract}

\section{Introduction}

$\sigma$-Bond metathesis reactions are now well-recognized reactions in the field of early transition metal, lanthanide, and actinide chemistry. ${ }^{1,2}$ They have been the subject of several theoretical studies ${ }^{2,3}$ which have shown how the presence of empty d metal orbitals is crucial for such $\left[2_{\mathrm{s}}+2_{\mathrm{s}}\right]$ processes. More recent experimental ${ }^{4}$ and theoretical ${ }^{5}$ findings, however, suggest that $\sigma$-bond metathesis reactions of $\mathrm{H}_{2}$ or $\mathrm{CH}_{4}$ could also occur with middle and late transition metal systems. From a theoretical point of view, we recently showed that threecoordinate $\mathrm{d}^{8}$ and five-coordinate $\mathrm{d}^{6}$ formate complexes could undergo a $\sigma$-bond metathesis reaction with $\mathrm{H}_{2}$ to yield formic acid. $^{6} \mathrm{~A}$ careful analysis of the molecular orbital pattern

* Corresponding author. Telefax: Int. code + (0) 388612085 . Email: dedieu@quantix.u-strasbg.fr.

$\dagger$ Université Louis Pasteur.

¥ Utrecht University.

${ }^{\otimes}$ Abstract published in Advance ACS Abstracts, June 1, 1997.

(1) (a) Jessop, P. G.; Morris, R. H. Coord. Chem. Rev. 1992, 121, 155. (b) Arndtsen, B. A.; Bergman, R. G.; Mobley, T. A.; Peterson, T. H. Acc. Chem Res. 1995, 28, 154 and references therein. (c) Crabtree, R. H. Acc. Chem. Res. 1995, 95, 987.

(2) Folga, E.; Woo, T.; Ziegler, T. In Theoretical Aspects of Homogeneous Catalysis; van Leeuwen, P. W. N. M., Morokuma, K., van Lenthe, J. H., Eds.; Kluwer: Dordrecht, The Netherlands, 1995; p 115 and references therein.

(3) (a) Steigerwald, M. L.; Goddard, W. A., III. J. Am. Chem. Soc. 1984, 106, 308. (b) Upton, T. A.; Rappé, A. K. J. Am. Chem. Soc. 1985, 107, 1206. (c) Jolly, C. A.; Marynick, D. S. J. Am. Chem. Soc. 1989, 111, 7968. (d) Cundari, T. R. J. Am. Chem. Soc. 1992, 114, 10557. (e) Ziegler, T.; Folga, E.; Berces, A. J. Am. Chem. Soc. 1993, 115, 636.

(4) (a) Joshi, A. M.; James, B. R. Organometallics 1990, 9, 199. (b) Burger, P.; Bergman, R. G. J. Am. Chem. Soc. 1993, 115, 10462 and references therein. (c) Hartwig, J. F.; Bhandari, S.; Rablen, P. R. J. Am. Chem. Soc. 1994, 116, 1839. (d) Morris, R. H. Inorg. Chem. 1992, 32, 1471. (e) Lee, J. C.; Peris, E.; Rheingold, A. L.; Crabtree, R. H. J. Am. Chem. Soc. 1994, 116, 11014. (f) Schlaf, M.; Morris R. H. J. Chem. Soc., Chem. Commun. 1995, 625. (g) Arndtsen, B. A.; Bergman, R. G.; Science 1995, 270, 1970.

(5) (a) Musaev, D. G.; Mebel, A. M.; Morokuma, K. J. Am. Chem. Soc. 1994, 116, 10693. (b) Versluis, L.; Ziegler, T. Organometallics 1990, 9, 2985. (c) Siegbahn, P. E. M.; Crabtree, R. H. J. Am. Chem. Soc. 1996, 118,4442 .

(6) (a) Hutschka, F.; Dedieu, A.; Leitner, W. Angew. Chem., Int. Ed. Engl. 1995, 34, 1742. (b) Hutschka, F.; Dedieu, A.; Eichberger, M.; Fornika, R.; Leitner, W. J. Am. Chem. Soc. 1997, 119, 4432. revealed that, in addition to the presence of an empty $\mathrm{d}_{\sigma}$ orbital on the metal, the presence of a lone pair on the oxygen atom of the formate ligand, which is not engaged in the bond to the metal and which is acting somehow as an external base, was critical for the heterolytic splitting of $\mathrm{H}_{2}{ }^{6 \mathrm{~b}}$ This implies that any ligand having such a lone pair, like the hydroxo or an alkoxo ligand, would be a good candidate for undergoing a $\sigma$-bond metathesis process. The reverse process, i.e. the $\sigma$-bond metathesis reaction of water or of an alcohol with a metal hydride or a metal alkyl complex, should be also feasible. Recent experimental work seems to indicate that this is indeed the case. ${ }^{7-11}$ But the intimate mechanism of such reactions has not been fully ascertained. ${ }^{11}$ In particular, since the alcohols that were found to be successful are relatively acidic, it is unclear whether they react via protonation through acid-base type equilibria (especially in the case of H-bonding solvent) or via a four centered transition state typical of a genuine $\sigma$-bond methathesis process. ${ }^{12}$ Although a theoretical study that does not take into account solvent effects cannot provide an unambiguous answer to this question, it should be quite helpful for delineating the factors that account for the $[2+2]$ mechanism in this type of chemistry with late transition metal

(7) Crabtree, R. H.; Lavin, M.; Bonneviot, L. J. Am. Chem. Soc. 1986, $108,4032$.

(8) (a) Kim, Y. J.; Osakada, K.; Takenada, A.; Yamamoto, A. J. Am. Chem. Soc. 1990, 112, 1096. (b) Komiya, S.; Akai, Y.; Tanaka, K.; Yamamoto, T.; Yamamoto, A. Organometallics 1985, 4, 1130. (c) Kim, Y. J.; Osakada, K.; Sugita, K.; Yamamoto, A.; Yamamoto, A. Organometallics 1988, 7, 2182. (d) Osakada, K.; Kim, Y. J.; Yamamoto, A. J. Organomet. Chem. 1990, 382, 303.

(9) Kegley, S. E.; Schaverien, C. J.; Freudenberger, J. H.; Bergman, R. G.; Nolan, S. P.; Hoff, C. D. J. Am. Chem. Soc. 1987, 109, 6563.

(10) Kapteijn, G. M.; Dervisi, A.; Grove, D. M.; Kooijman, H.; Lakin, M. T.; Spek, A. L.; van Koten, G. J. Am. Chem. Soc. 1995, 117, 10939.

(11) For a review of metathesis or exchange reactions involving late transition metal hydroxide or alkoxide complexes, see: Bryndza, H. E.; Tam, W. Chem. Rev. 1988, 88, 1163.

(12) Related to this question is the mechanism of alkoxide exchange reactions in metal alkoxide complexes that can proceed via a dissociative mechanism where the alkoxide ligand is dissociated prior to exchange or via an associative mechanism where the transition state for interchange has both hydrogen atom transfer and proton transfer character. ${ }^{11,13}$

(13) Simpson, R. D.; Bergman, R. G. Organometallics 1993, 12, 781. 
complexes. The results that we report here pertain to this aspect of the problem. They have been obtained by investigating the model reactions $(1)-(8)$. A comparison between reactions 1<smiles>[Y][R]([H])(NCC)O[R]([Y])([H])NCCCCCCC</smiles>



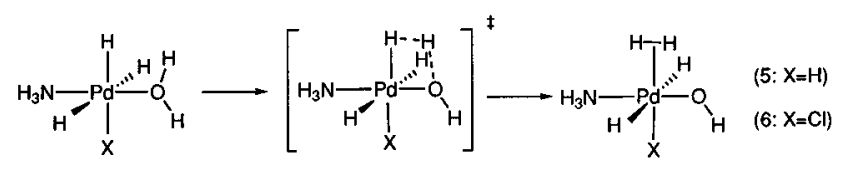

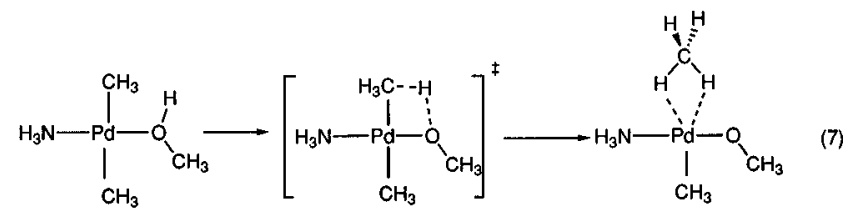

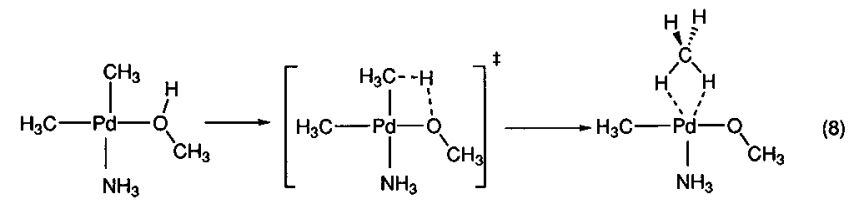

and 2 or between reactions 3 and 4 allows us to study the trans influence of the ligand trans to the leaving and incoming groups, respectively. The influence of carrying out the metathesis reaction in a $\mathrm{d}^{6}$ hexacoordinated environment of the metal rather instead of a d $\mathrm{d}^{8}$ tetracoordinated environment is analyzed by comparing either reactions 5 and 1 or reactions 6 and 2. Finally we turn to a reaction that is closer to the ones that have been carried out experimentally by looking at the $\sigma$-bond metathesis reactions of methanol with palladium methyl complexes; see reactions 7 and 8 .

\section{Computational Details}

SCF and MP2 calculations were carried out using the Gaussian 92 and Gaussian 94 program systems, optimizing at both levels the geometry by a gradient geometry optimization. ${ }^{14}$ Our previous studies on the $\sigma$-bond metathesis of $\mathrm{H}_{2}$ with formate-rhodium complexes,

(14) (a) Frisch, M. J.; Trucks, G. W.; Head-Gordon, M.; Gill, P. M. W.; Wong, M. W.; Foresman, J. B.; Johnson, B. G.; Schlegel, H. B.; Robb, M. A.; Reploge, E. S.; Gomperts, R.; Andres, J. L.; Raghavachari, K.; Binkley, J. S.; Gonzales, C.; Martin, R. L.; Fox, D. J.; Defrees, D. J.; Baker, J.; Stewart, J. J. P.; Pople, J. A. Gaussian 92, Revision E.2; Gaussian, Inc., Pittsburgh PA, 1992. (b) Frisch, M. J.; Trucks, G. W.; Schlegel, H. B.; Gill, P. M. W.; Johnson, B. G.; Robb, M. A.; Cheeseman, J. R.; Keith, T.; Petersson, G. A.; Montgomery, J. A.; Raghavachari, K.; Al-Laham, M. A.; Zakrzewski, V. G.; Ortiz, J. V.; Foresman, J. B.; Peng, C. Y.; Ayala, P. Y.; Chen, W.; Wong, M. W.; Andres, J. L.; Reploge, E. S.; Gomperts, R.; Martin, R. L.; Fox, D. J.; Binkley, J. S.; Defrees, D. J.; Baker, J.; Stewart, J. P.; Head-Gordon, M.; Gonzales, C.; Pople, J. A. Gaussian 94, Revision B.2.; Gaussian, Inc.: Pittsburgh, PA, 1995. (c) Total MP2//MP2 energies (au): 1, -259.6011; TS1, -259.5810; 9, -259.6044; 2, -718.0434; TS2, $-717.9773 ; \mathbf{1 0},-717.9918 ; \mathbf{3},-259.6509 ; \mathbf{T S 3},-259.5913 ; \mathbf{1 1}$, $-259.6048 ; \mathbf{4},-718.0329 ;$ TS4, $-717.9819 ; \mathbf{1 2},-717.9953 ; \mathbf{5}$, -260.6733; TS5, -260.6482; 13, -260.6822; 6, -719.0944; TS6, $-719.0217 ; \mathbf{1 3},-719.0354 ; 7,-376.8608 ;$ TS7, $-376.8418 ; \mathbf{1 4}$, $-376.8944 ; \mathbf{8},-376.8901$; TS8, $-376.8509 ; \mathbf{1 5},-376.8799$. which were done at both the MP2//MP2 and QCISD(T)//MP2 levels, showed that the MP2//MP2 level was appropriate for studying this type of reaction, the activation energies as the reaction energies differing by less than $5 \mathrm{kcal} \mathrm{mol}^{-1}$ between the two levels. ${ }^{6 \mathrm{~b}}$ Moreover our interest here is in the comparison of the various reactions, i.e. in $\Delta \Delta E$ values rather than in $\Delta E$ values. Thus, recomputing energies at a better level such as QCISD(T) would not lead to a substantial improvement. The basis set used in the study of reactions 1-6 were as follows: For the palladium atom, the 28 innermost core electrons (up to $3 \mathrm{~d}$ ) were described by the relativistic pseudopotential of Hay and Wadt ${ }^{15}$ and the remaining outer core and valence electrons by an $(8,6,4)\langle 3,3,2\rangle$ basis set. ${ }^{15}$ For the first-row atoms, the chlorine atom and the hydrogen atoms of $\mathrm{NH}_{3}$, the $(9,5),(11,7)$, and (4) basis sets of Huzinaga ${ }^{16}$ contracted respectively into $\langle 3,2\rangle,\langle 4,3\rangle$, and $\langle 2\rangle$ were used. The hydrides of the reaction plane were described by a somewhat more flexible basis set, $(6,1)$ contracted into $\langle 3,1\rangle,{ }^{16 a}$ the exponent of the added $\mathrm{p}$ polarization function being 0.8 . For the sake of consistency between the reacting entities, a d polarization function (of exponent $\alpha_{d}=1.00$ ) and a p polarization function (of exponent $\alpha_{p}=0.8$ ) were also added to the oxygen and hydrogen atoms of water. The two hydrides out of the plane of reaction 5 were described by the (4) $\langle 2\rangle$ basis set. In order to perform analytical frequency calculations on the transition states an all-electron $(16,11,9)\langle 7,5,5\rangle$ basis set was used for palladium. ${ }^{17}$ The geometry was therefore reoptimized with this allelectron basis, yielding geometries very close to the geometries optimized with the pseudopotential basis set (see for instance the values quoted for TS1 in Figure 1). For reactions 7 and 8, the same basis set was used for palladium and the first-row atoms. The carbon and oxygen atoms were augmented by polarization functions of exponent $\alpha_{d}=0.63$ and 1.00 , respectively. All hydrogen atoms were described by a (4) $\langle 2\rangle$ basis set. ${ }^{16 a, 18}$

\section{Results and Discussion}

The optimized structures of the water and methanol complexes, of the transition states for the $\sigma$-bond metathesis reactions, and of the $\mathrm{H}_{2}$ and $\mathrm{CH}_{4}$ primary products of reactions 1-8 are shown in Figures 1-4 together with the associated energy changes and the charges of the atoms or groups of atoms directly involved in the reaction.

The computed $\mathrm{Pd}-\mathrm{O}$ distances in the aquo complexes $\mathbf{1}, \mathbf{2}$, and $\mathbf{4}$ compare well with the few known experimental values, ${ }^{19}$ which lie in the range $2.13-2.21 \AA$. The value of $2.40 \AA$ found for 3 may seem much too long. But it results from a combination of two factors, the strong trans influence of the hydride ligand trans to $\mathrm{H}_{2} \mathrm{O}$ and a repulsive electrostatic

(15) Hay, P. J.; Wadt, W. R. J. Chem. Phys. 1985, 82, 270

(16) (a) Huzinaga, S. J. Chem. Phys. 1965, 42, 1293. (b) Huzinaga, S. Technical Report, University of Alberta, Edmonton, Canada, 1971.

(17) (a) Veillard, A.; Dedieu, A. Theor. Chim Acta 1984, 65, 215. (b) The original $(15,9,8)$ basis set was modified by the addition of an $\mathrm{s}$ function of exponent 0.30560 to suppress the gap between the functions needed to describe the widely separated $4 \mathrm{~s}$ and $5 \mathrm{~s}$ shells, two $\mathrm{p}$ functions of exponents 0.23560 and 0.08386 , and one d function of exponent 0.07890 .

(18) For consistency reasons, the hydrogen atoms of the two methyl ligands and of the methanol of reactions 4 and 5 cannot be described differently. Putting polarization functions on these atoms to have a basis set rigorously similar to the one used for reactions $1-3$ would have added 60 extra contracted functions and thus brought the calculations above our current computational limits. We have verified however with pilot calculations carried out for the reaction $\left[\mathrm{Pd}(\mathrm{H})_{2}\right.$ $\left.\left(\mathrm{NH}_{3}\right)\left(\mathrm{CH}_{3} \mathrm{OH}\right)\right] \rightarrow\left[\mathrm{Pd}(\mathrm{H})\left(\mathrm{NH}_{3}\right)\left(\mathrm{H}_{2}\right)\left(\mathrm{OCH}_{3}\right)\right]$ that the addition of $\mathrm{p}$ polarization functions on the hydrides bound to the metal and on the reacting methoxy hydrogen atom did not change the results significantly: the MP2//MP2 energy barrier increased by only $2.8 \mathrm{kcal} \mathrm{mol}^{-1}$, from 13.9 to $16.7 \mathrm{kcal} \mathrm{mol}^{-1}$.

(19) (a) Deeming, A. J.; Rothwell, I. P.; Hursthouse, M. B.; New, L. J. Chem. Soc., Dalton Trans. 1978, 1490. (b) Castan, P.; Jaud, J.; Wimmer, S.; Wimmer, L. J. Chem. Soc., Dalton Trans. 1991, 1155. (c) Leoni, P.; Sommovigo, M.; Pasquali, M.; Midollini, S.; Braga, D.; Sabatino, P. Organometallics 1991, 10, 1038. (d) Stang, P. J.; Cao, D. H.; Poulter, G. T.; Arif, A. M. Organometallics 1995, 14, 1110. (e) Kickham, J. E.; Loeb, S. J. Organometallics 1995, 14, 3584. 

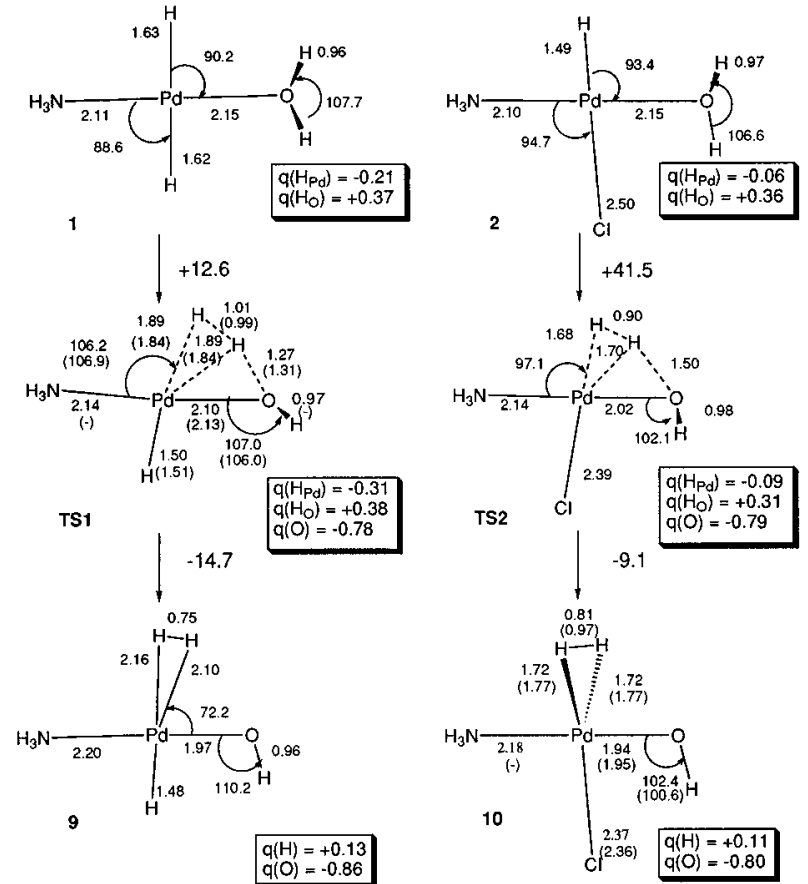

Figure 1. MP2 optimized geometries, relative energies (in $\mathrm{kcal} \mathrm{mol}^{-1}$ ), and selected atomic charges (as obtained from the RHF Mulliken population analysis) of the water complex, transition state, and dihydrogen product of the $\sigma$-bond metathesis reactions (1) and (2). The values in parentheses refer to the calculations with the all-electron basis for palladium. In the transition state, $q\left(\mathrm{H}_{0}\right)$ refers to the charge of the transferred hydrogen atom.
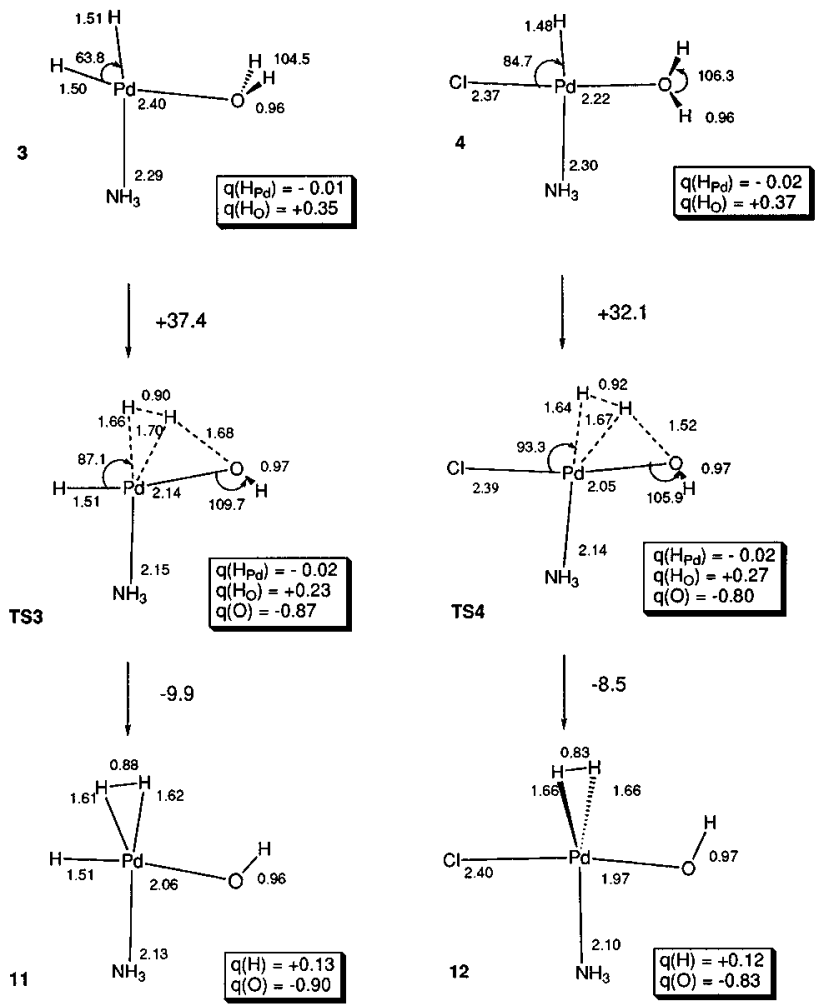

Figure 2. MP2 optimized geometries, relative energies (in $\mathrm{kcal} \mathrm{mol}^{-1}$ ), and selected atomic charges (as obtained from the RHF Mulliken population analysis) of the water complex, transition state, and dihydrogen product of the $\sigma$-bond metathesis reactions (3) and (4). In the transition state, $q\left(\mathrm{H}_{0}\right)$ refers to the charge of the transferred hydrogen atom.

interaction between the oxygen atom and the $\mathrm{Pd}$ atom. The strong trans influence of the hydride is best exemplified by the


13

$q(H)=+0.08$
$q(O)=-0.71$

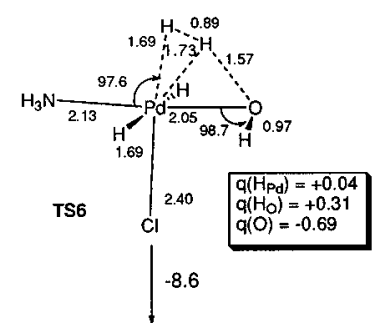

Figure 3. MP2 optimized geometries, relative energies (in $\mathrm{kcal} \mathrm{mol}^{-1}$ ), and selected atomic charges (as obtained from the RHF Mulliken population analysis) of the water complex, transition state, and dihydrogen product of the $\sigma$-bond metathesis reactions (5) and (6). The values in parentheses refer to the calculations with the all-electron basis for palladium. In the transition state, $q\left(\mathrm{H}_{0}\right)$ refers to the charge of the transferred hydrogen atom.

elongation of the $\mathrm{Pd}-\mathrm{NH}_{3}$ bond between $\mathbf{1}$ and 3 . The repulsive electrostatic interaction is due to the negative charge borne by the metal atom in the cis hydride complex. ${ }^{20}$ The $\mathrm{Pd}-\mathrm{O}$ distance in the methanol complex is also in agreement with the $\mathrm{Pd}-\mathrm{O}$ distance found in the $\mathrm{X}$-ray crystal structure of [Pd$\left\{\mathrm{C}_{6} \mathrm{H}_{4}\left(\mathrm{CH}_{2} \mathrm{CH}_{2} \mathrm{OH}\right)-2\right\}$ (tmeda) $\left.]\left(\mathrm{NO}_{3}\right)\right]:{ }^{24}$ the somewhat shorter experimental bond length may be ascribed to the cationic nature of the tmeda system. Moreover the elongation of $0.15 \AA$ that we find between $\mathbf{1 5}$ and $\mathbf{7}$ does correspond to the one (0.16 $\AA$ ) that has been experimentally inferred when an alkoxide ligand trans to a tertiary amine is protonated. ${ }^{24}$

The transition states of reactions 1-6, TS1-TS6, were characterized by a frequency analysis. They all display an imaginary frequency corresponding to a $\sigma$ bond metathesis process as shown in Chart 1 for TS1. ${ }^{25}$ They are product-like, the $\mathrm{H} \cdots \mathrm{H}$ distance being relatively short (this feature is more

(20) The negative charge of $\mathrm{Pd}$ is computed to be $-0.16 \mathrm{e}$ in 3 instead of $+0.10 \mathrm{e}$ in 1 (HF Mulliken population analysis). The two "hydrides" also behave differently: the charge is almost zero in $\mathbf{3}$ whereas it amounts to $-0.21 \mathrm{e}$ and $-0.23 \mathrm{e}$ in 1 . This feature can be rationalized as follows: the cis arrangement of the two hydrides involves sd hybridization of palladium (with a quite important $4 \mathrm{~d}$ mixing reflected in the small $\mathrm{H}-\mathrm{Pd}-\mathrm{H}$ angle ${ }^{21,22}$ ) whereas the trans arrangement involves sp hybridization. The covalency is optimal for the cis arrangement.

(21) (a) Schilling, J. B.; Goddard, W. A., III; Beauchamp, J. L. J. Phys. Chem. 1987, 91, 4470. (b) Siegbahn, P. E. M. Theor. Chim. Acta. 1994, 87,441 .

(22) Note also that a small $\mathrm{H}-\mathrm{Pd}-\mathrm{H}$ angle has been found in the CASSCF+CI geometry optimization of the $\mathrm{PdH}_{2}$ moiety in $\left(\mathrm{H}_{2} \mathrm{O}\right)_{2}$ $\mathrm{PdH}_{2}{ }^{23}$

(23) Brandemark, U. B.; Blomberg, M. R. A.; Pettersson, L. G. M.; Siegbahn, P. E. M. J. Phys. Chem. 1984, 88, 4617.

(24) Alsters, P. L.; Boersma, J.; Smeets, W. J. J.; Spek, A. L.; van Koten, G. Organometallics 1993, 12, 1639. 

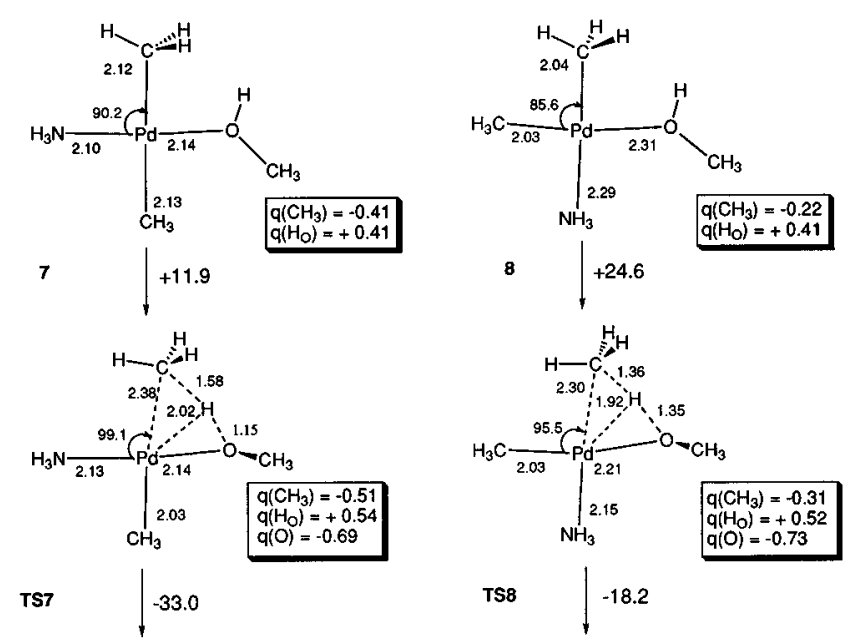

TS7 $\quad-33.0$


Figure 4. MP2 optimized geometries, relative energies (in $\mathrm{kcal} \mathrm{mol}^{-1}$ ), and selected atomic charges (as obtained from the RHF Mulliken population analysis) of the methanol complex, transition state, and methane product of $\sigma$-bond metathesis reactions (7) and (8). In the transition state, $q\left(\mathrm{H}_{0}\right)$ refers to the charge of the transferred hydrogen atom.

\section{Chart 1}

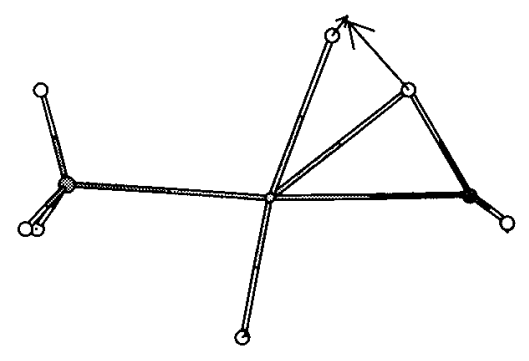

pronounced when $\mathrm{Cl}$ is in the coordination sphere, consistent with the fact that in this case the reaction is highly endothermic). The $\mathrm{O} \cdots \mathrm{H}$ distance is strongly reaction dependent, ranging from ca. $1.26 \AA$ in TS1 and TS5 to $1.70 \AA$ in TS3. On the other hand, the $\mathrm{H} \cdots \mathrm{H} \cdots \mathrm{O}$ angle remains practically constant, varying from 149 to $155^{\circ}$ only. This quite large angle is most likely due to the requirement for a linear proton transfer. ${ }^{26}$ The greater variation of the $\mathrm{H} \cdots \mathrm{H}$ and $\mathrm{O} \cdots \mathrm{H}$ distances can then be explained by the adjustement of the remainder of the molecule to this constraint. Also noteworthy in the structure of these transition states is the fact that the nonreacting hydrogen atom of the incipient hydroxyl ligand is always found out of the plane of

(25) The analytically computed imaginary frequencies are as follows: TS1, $1233 i \mathrm{~cm}^{-1}$; TS2, $981 i \mathrm{~cm}^{-1}$; TS3, $614 i \mathrm{~cm}^{-1}, 102 i \mathrm{~cm}^{-1}$; TS4, $973 i$ $\mathrm{cm}^{-1}, 54 i \mathrm{~cm}^{-1}$; TS5, $1434 i \mathrm{~cm}^{-1}, 84 i \mathrm{~cm}^{-1}$; TS6, $818 i \mathrm{~cm}^{-1}$. The extra imaginary frequencies found for TS3-TS5 are quite low and correspond to a rotational movement of the $\mathrm{NH}_{3}$ hydrogen atoms which was kept frozen during the optimization process. The corresponding eigenvectors are all similar to the one shown for TS1 in Chart 1. We have not carried out a frequency calculation for the much larger TS7 and TS7 structures, but the approximate Hessian obtained at the end of the geometry optimization was very similar to the ones obtained at the end of the geometry optimization of TS1-TS6.

(26) (a) Scheiner, S. Acc. Chem. Res. 1994, 27, 402. (b) Wolf, S.; Kim, C. K.; Yang, K.; Weinberg, N.; Shi, Z. J. Am. Chem. Soc. 1995, 117, 4240 . the reaction. ${ }^{27}$ We will show later that this orientation contributes to the stabilization of the transition states.

In contrast, a variety of rotational isomers (with respect to the rotation around the $\mathrm{Pd}-\mathrm{O}$ bond) is obtained for the hydroxyl products. The relative stability of the $\mathrm{OH}$ rotational isomers is governed by the balance between the electrostatic interactions of the hydroxyl hydrogen atom with the ancillary ligands (which is attractive with either the chloride or the hydride and repulsive with $\left.\mathrm{NH}_{3}\right)^{28}$ and the four-electron repulsion between the $\mathrm{OH} \mathrm{p}$ lone pair and the Pd doubly occupied $\mathrm{d}_{\pi}$ orbital of appropriate symmetry. The structure of water complexes $\mathbf{1 - 6}$ can be explained similarly. For instance the orientation of $\mathrm{H}_{2} \mathrm{O}$ in 2 is such that one has a favorable electrostatic interaction between the positively charged hydrogen atom and the chloride ligand. On the other hand, in $\mathbf{4}$, where the chloride ligand is trans to $\mathrm{H}_{2} \mathrm{O}$, the orientation of the water molecule minimizes the repulsive interaction between the lone pair not engaged in the $\mathrm{Pd}-\mathrm{O} \sigma$ bond and the palladium $\mathrm{d}_{\pi}$ orbital.

Similar features are found in reactions 7 and 8: the methyl group lies out of the plane of the reaction in the transition states TS7 and TS8 but in the coordination plane of either the reactants or the products. We did not perform a frequency analysis for TS7 and TS8, but the geometrical features are quite consistent with the ones found for TS1-TS4 and for the transition state of the $\sigma$-bond metathesis reaction between $\mathrm{H}_{2}$ and $\left[\mathrm{Rh}\left(\mathrm{PH}_{3}\right)_{2}\left(\eta^{1}\right.\right.$ $\left.\mathrm{O}_{2} \mathrm{CH}\right)$ ] that we have analyzed previously. ${ }^{6}$ Note, finally, the out of plane disposition of either $\mathrm{H}_{2}$ or $\mathrm{CH}_{4}$ in products 1016. In $9, \mathrm{H}_{2}$ lies in the coordination plane. A similar disposition has been found for $\left[\mathrm{Pt}(\mathrm{H})\left(\mathrm{PH}_{3}\right)_{2}\left(\mathrm{H}_{2}\right)\right]^{+}{ }^{30}$ But in all systems investigated so far and as in $\left[\mathrm{Pt}(\mathrm{H})\left(\mathrm{PH}_{3}\right)_{2}\left(\mathrm{H}_{2}\right)\right]^{+}$, the rotational barrier is very small (of the order of $1 \mathrm{kcal} \mathrm{mol}^{-1}$ for $\mathrm{H}_{2}$ and slightly more for $\mathrm{CH}_{4}$ ).

A look at the energy profiles of reactions $1-8$ reveals some interesting trends with respect to the ligand environment. Reactions 1 and 2, like reactions 5 and 6, differ only in the ligand trans to the leaving group; the replacement of $\mathrm{H}$ by $\mathrm{Cl}$ (which has a much smaller trans influence) increases the barrier by about $30 \mathrm{kcal} \mathrm{mol}^{-1}$. The energy barriers of reactions 7 and 8 (which are also characterized by a similar $\mathrm{Cl} / \mathrm{H}$ substitution) differ by about the same amount (note however that in these two reactions the ligand cis to the leaving group is also exchanged). Thus it would seem that a decrease in the trans influence of the ligand trans to the leaving group would result in an increase of the energy barrier. By reasoning along similar lines for the ligand trans to the incoming group, one would then expect that a decrease in the trans influence would lead to a decrease of the energy barrier. This is indeed the case for reactions 3 and 4, where the incoming group is $\mathrm{H}_{2} \mathrm{O}$, or for the microscopic reverse of reactions of 1 and 2 , in which the incoming group is $\mathrm{H}_{2}$. But in both cases the barrier decreases by only $5 \mathrm{kcal} \mathrm{mol}^{-1}$. Moreover, in the microscopic reverse of reactions 3 and 4, the substitution of $\mathrm{H}$ by $\mathrm{Cl}$ does not cause any change in the barrier height! One cannot therefore rationalize these trends only in terms of the trans influence of the ligand trans to the leaving group or to the entering group. In fact, one should not expect the trans influence to govern the

(27) The $\mathrm{H}-\mathrm{Pd}-\mathrm{O}-\mathrm{H}$ dihedral angles are 104.7, 121.8, 99.6, 93.1, 101.0, and $109.1^{\circ}$ in TS1-TS6, respectively.

(28) An attractive electrostatic interaction between the hydridic $\mathrm{Ir}-\mathrm{H}$ and the electron-deficient $\mathrm{OH}$ proton has been postulated to rationalize the bending of the $\mathrm{O}-\mathrm{H}$ group toward the hydride in $c i s-[\operatorname{Ir}(\mathrm{H})(\mathrm{OH})$ $\left.\left(\mathrm{PMe}_{3}\right)_{4}\right] \mathrm{PF}_{6} \cdot{ }^{29}$

(29) (a) Milstein, D.; Calabrese, J. C.; Williams, I. D. J. Am. Chem. Soc. 1986, 108, 6387. (b) Stevens, R. C.; Bau, R.; Milstein, D.; Blum, O.; Koetzle, T. F. J. Chem. Soc., Dalton Trans. 1990, 1429.

(30) Gusev, D. G.; Notheis, J. U.; Rambo, J. R.; Hauger, B. E.; Eisenstein, O.; Caulton, K. G. J. Am. Chem. Soc. 1994, 116, 7409. 
differences in the activation energy of the process, since the elongation in the transition states of either the $\mathrm{Pd}-\mathrm{H}$ bond or the $\mathrm{Pd}-\mathrm{CH}_{3}$ bond is quite moderate (less than $0.3 \AA$ ). Thus, the energy demand for this elongation is much smaller than the bond dissociation energy and the differences between elongation energies are negligible. Taking $\mathbf{1}$ and $\mathbf{2}$ as an example, one finds elongation energies of 5.3 and $5.9 \mathrm{kcal} \mathrm{mol}^{-1}$, respectively. ${ }^{31}$ Their difference amounts to $0.6 \mathrm{kcal} \mathrm{mol}^{-1}$ and cannot clearly account for a difference of $28.9 \mathrm{kcal} \mathrm{mol}^{-1}$ of the energy barriers.

On the other hand, the charge distribution in the various reactants and more specifically the charges of the two entities that are brought toward each other during the process seem to provide a better rationalization of the results. This is not surprising since $\sigma$-bond metathesis reactions involve heterolytic splittings. The charge distributions displayed in Figures 1-4 are clearly indicative of some correlation between the charge distribution and the barrier height for a given oxidation state of the metal and a given combination of incoming and leaving groups. Thus, when $\mathrm{H}_{2} \mathrm{O}$ is the incoming group and $\mathrm{H}_{2}$ the leaving group (Figures 1 and 2), the barrier is rather moderate when the hydride has a charge of -0.21 as in $\mathbf{1}$. However the barrier rises by $20 \mathrm{kcal} \mathrm{mol}^{-1}$ or more when the hydride is much less negatively charged because of the presence of the strongly electron-attractive chloride ligand as in $\mathbf{2}$ or $\mathbf{4}$ or because of the cis disposition of the two hydrides as in $3 .^{20}$ A similar feature is found with the $\mathrm{d}^{6}$ systems of reactions 5 and 6 (Figure $3)^{32}$ or of reactions 7 and 8 , in which $\mathrm{CH}_{3} \mathrm{OH}$ is the incoming group; see Figure 4. In the latter case, however, the increase in the barrier is smaller. These features are in line with the fact that the occurrence of a $\sigma$-bond metathesis reaction between Pd(II) methyl complexes and various alcohols depends on the $\mathrm{p} K_{\mathrm{a}}$ of the alcohol. ${ }^{8,10}$ We can assess, by comparing the energy barrier of reaction 1 to the energy barrier computed for the reaction $\left[\mathrm{Pd}(\mathrm{H})_{2}\left(\mathrm{NH}_{3}\right)\left(\mathrm{CH}_{3} \mathrm{OH}\right)\right] \rightarrow\left[\mathrm{Pd}(\mathrm{H})\left(\mathrm{NH}_{3}\right)\left(\mathrm{H}_{2}\right)\left(\mathrm{OCH}_{3}\right)\right],{ }^{18}$ the relative performance of $\mathrm{H}_{2} \mathrm{O}$ and $\mathrm{CH}_{3} \mathrm{OH}$ as entering groups: The energy barrier increases from $12.6 \mathrm{kcal} \mathrm{mol}^{-1}\left(\mathrm{H}_{2} \mathrm{O}\right.$ case) to $16.7 \mathrm{kcal} \mathrm{mol}^{-1}\left(\mathrm{CH}_{3} \mathrm{OH}\right.$ case $)$, again in the same direction as the $\mathrm{p} K_{\mathrm{a}}$ variation.

When the incoming groups is either $\mathrm{H}_{2}$ or $\mathrm{CH}_{4}$ and the respective leaving group either $\mathrm{H}_{2} \mathrm{O}$ or $\mathrm{CH}_{3} \mathrm{OH}$, the correlation still holds but is somewhat poorer. The computed barriers do not vary significantly for the microscopic reverse reactions of (1)-(4); see Figures 1 and 2. This is partly due to a leveling effect of the large negative charge of the bound oxygen atom. Moreover, the positive charge of the reacting hydrogen atom of $\mathrm{H}_{2}$ remains practically constant. On the other hand, the significant decrease of the energy barrier (from 33.0 to 18.2 $\mathrm{kcal} \mathrm{mol}^{-1}$; see Figure 4) on going from the microscopic reverse of reaction 7 to the microscopic reverse of reaction 8 cannot be traced only to the increase (from 0.97 to 1.06 ) in the charge separation between hydrogen and oxygen.

It is therefore clear that these $\sigma$-bond metathesis reactions, which involve either $\mathrm{H}_{2} \mathrm{O}$ or $\mathrm{CH}_{3} \mathrm{OH}$, occur readily (at least in the gas phase) when the electrostatics is favorable. Yet, such processes are formally forbidden (in the Woodward-Hoffmann sense). Thus one needs to analyze more deeply and look at the molecular orbitals that are involved in the reaction. As in early transition metal chemistry, ${ }^{3}$ the allowance of such

(31) These values were computed at the MP2 level on the optimized structures of $\mathbf{1}$ and $\mathbf{2}$ modified by elongating the $\mathrm{Pd}-\mathrm{H}$ bond up to 1.89 and $1.68 \AA$, respectively (these values are the ones found for TS1 and TS2).

(32) We note that, in $\mathbf{5}$, the hydride is only slightly negative. But in $\mathbf{6}, \mathrm{H}$ is positively charged. Thus, the correlation still holds for this set of two reactions.

processes can be a priori ascribed to the presence of an empty $\mathrm{d}_{\sigma}$ orbital, either in the $\mathrm{d}^{8}$ three-coordinate $\mathrm{T}$-shaped fragment or in the $\mathrm{d}^{6}$ five-coordinate square pyramidal fragment: the phase relationship of this orbital which is metal-ligand antibonding (see 17a and 17b) is such that it can interact positively

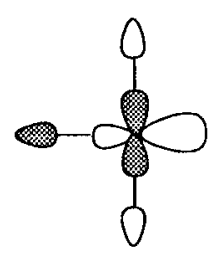

$17 a$

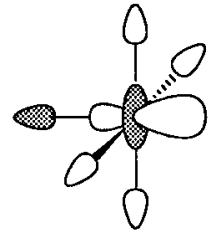

$17 b$

with the incoming $\sigma$-bond orbital (see 18a and 18b). Its metal-

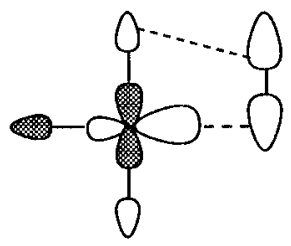

$18 \mathrm{a}$

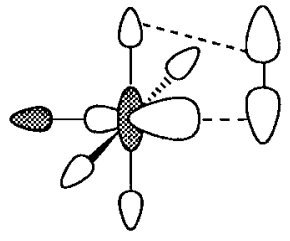

$18 b$

ligand bonding counterpart can in turn interact positively with the $\sigma^{*}$ orbital of the incoming reactant, as shown schematically in 19a and 19b. If one takes reaction 1 and its transition state

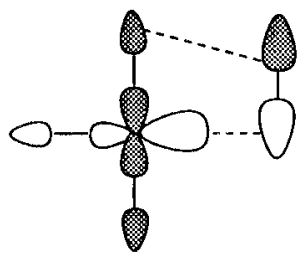

$19 a$

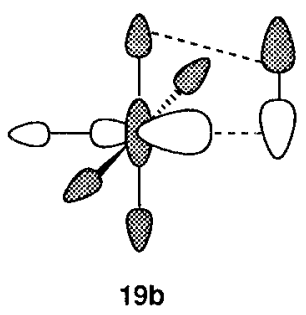

TS1 as prototypes, one indeed finds such interactions. The analog of interaction 19a is found in the HOMO of TS1. In this orbital, the bonding combination between the $\left[\mathrm{s}_{\mathrm{H}}+\mathrm{d}_{\left.x^{2}-y^{2}\right]}\right.$ orbital and $\sigma^{*} \mathrm{H}_{2} \mathrm{O}$ is destabilized by the $\sigma$ lone pair of $\mathrm{H}_{2} \mathrm{O}$; see the interaction diagram in Figure 5 and the density contour plots in Figure $6 .{ }^{33}$ The analog of $\mathbf{1 8 a}$, which is the interaction

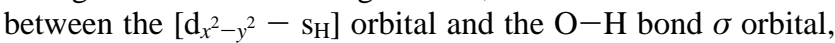
is much weaker due to energy mismatch. But this detrimental feature is overcome by the involvement, in the interaction pattern, of the $\mathrm{p}$ lone pair of $\mathrm{H}_{2} \mathrm{O}$. This second lone pair is perpendicular to the $\mathrm{O}-\mathrm{H}-\mathrm{O}$ plane. It can mix with the other orbitals during the metathesis process, thus allowing a continuous rehybridization which maintains the best overlap between the reacting entities. This mixing is best exemplified by the structure of the transition state which has, as noted before, a pyramidal environment of the oxygen atom rather than a planar one. Thus the $\mathrm{p}$ lone pair of $\mathrm{H}_{2} \mathrm{O}$, which a better electron donor than the $\sigma$ lone pair, can be used (instead of the $\sigma$ lone pair) to maintain a bonding interaction with the empty $\mathrm{Pd} \mathrm{d}_{\sigma}$ orbital; ${ }^{34}$ see the interaction diagram in Figure 5 and the density contour

(33) The contour diagrams have been obtained by using the MOLDEN package. MOLDEN was written by G. Schaftenaar, CAOS/CAMM Center Nijmegen, The Netherlands, 1991.

(34) The differential in the electron-donor ability of the lone pairs of an alkoxy group has been shown to control the rotational isomerism around the $\mathrm{Ir}-\mathrm{O}$ bond in distorted trigonal pyramidal $\mathrm{d}^{6} \mathrm{IrH}_{2}(\mathrm{OR}) \mathrm{L}_{2}$. Here, too, the rationale lies in a preferential interaction of the $\mathrm{p}$ lone pair with an empty d metal orbital. ${ }^{35}$

(35) Riehl, J. F.; Jean, Y.; Eisenstein, O.; Pélissier, M. Organometallics 1992, 11, 729 . 


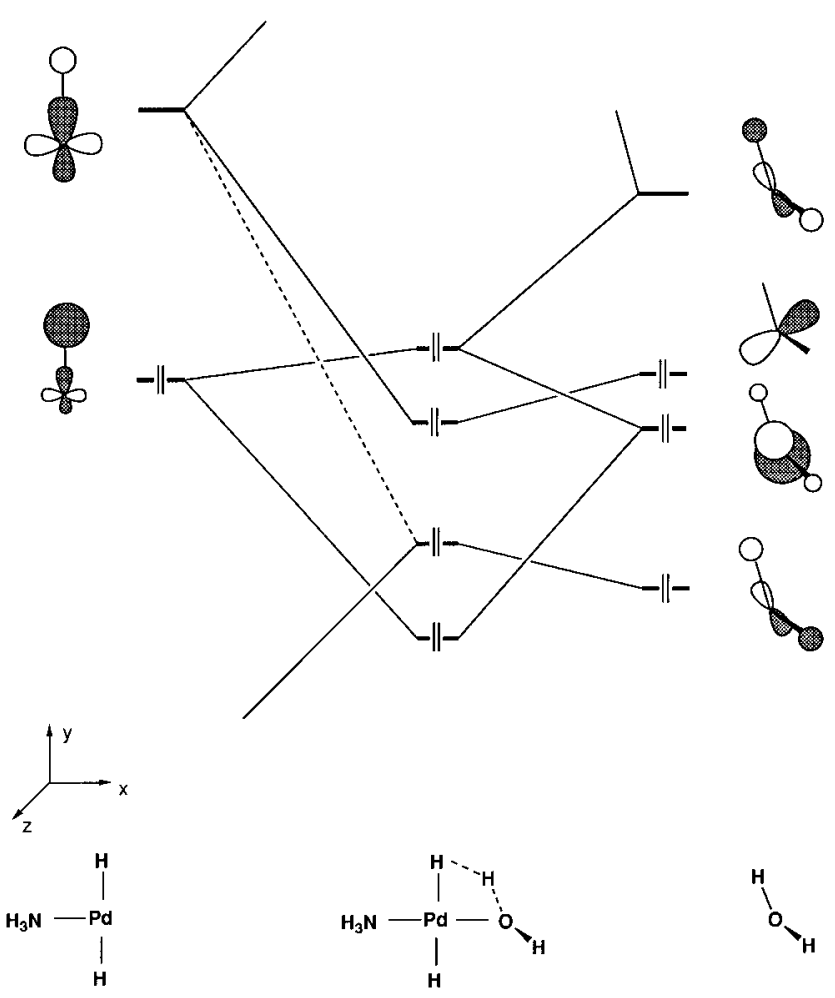

Figure 5. Diagram showing the orbital interaction between the $\mathrm{H}_{2} \mathrm{O}$ and $\mathrm{Pd}(\mathrm{H})_{2}\left(\mathrm{NH}_{3}\right)$ fragments based on the localized orbitals of TS1.

plots of the sub-HOMO shown in Figure 7. The net result is a stabilization of the transition state. This stabilizing effect can be quantified by computing a "transition state" for reaction 1 under $C_{s}$ symmetry constraints and comparing it to TS1. The corresponding structure, shown in $\mathbf{2 0},{ }^{36}$ is such that the $\mathrm{H}_{2} \mathrm{O}$

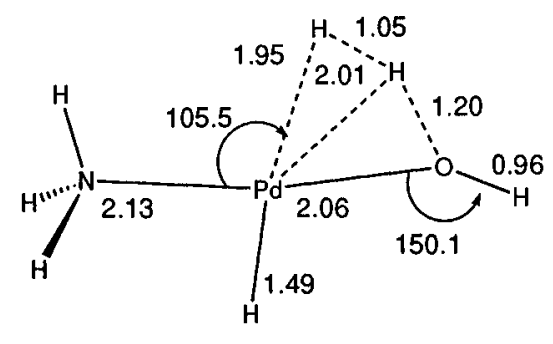

20

lone pair now interacting with the $\mathrm{Pd} \mathrm{d}_{\sigma}$ orbital is the $\sigma$ lone pair and no longer the p lone pair. 20 is destabilized by 7.9 $\mathrm{kcal} \mathrm{mol}{ }^{-1}$ with respect to TS1. Another indication of the importance of an additional lone pair in assisting such reactions is our failure to locate a transition state corresponding to a $\sigma$-bond metathesis mechanism for the hydrogen exchange in the reaction of $\mathrm{H}_{2}$ with $\left[\mathrm{Pd}(\mathrm{H})_{2}\left(\mathrm{NH}_{3}\right)\right]$.

We previously pointed out ${ }^{6}$ that the isolobal analogy between the $\mathrm{T}$-shaped $\mathrm{d}^{8}\left[\mathrm{ML}_{3}\right]$ and the square pyramidal $\mathrm{d}^{6}\left[\mathrm{ML}_{5}\right]$ systems ${ }^{37}$ could be used to account for $\sigma$-bond metathesis reactions occurring in $\mathrm{d}^{6}$ hexacoordinated complexes. This is borne out by the similar values of the energy barriers of reactions

(36) Structure 20 illustrates the compromise between the need for a more or less linearity of the $\mathrm{H} \cdots \mathrm{H} \cdots \mathrm{O}$ moiety and the need for the best possible interaction of the $\mathrm{H}_{2} \mathrm{O} \sigma$ lone pair with $\mathrm{Pd}$. This compromise results in quite long $\mathrm{Pd}-\mathrm{H}$ bonds and a larger $\mathrm{Pd}-\mathrm{O}-\mathrm{H}$ angle.

(37) (a) Hoffmann, R. Angew. Chem. 1982, 94, 781; Angew. Chem., Int. Ed. Engl. 1982, 21, 711. (b) Albright, T. A.; Burdett, J. K.; Whangbo, M. H. Orbital Interactions in Chemistry; Wiley: New York, 1985; pp 352-356.
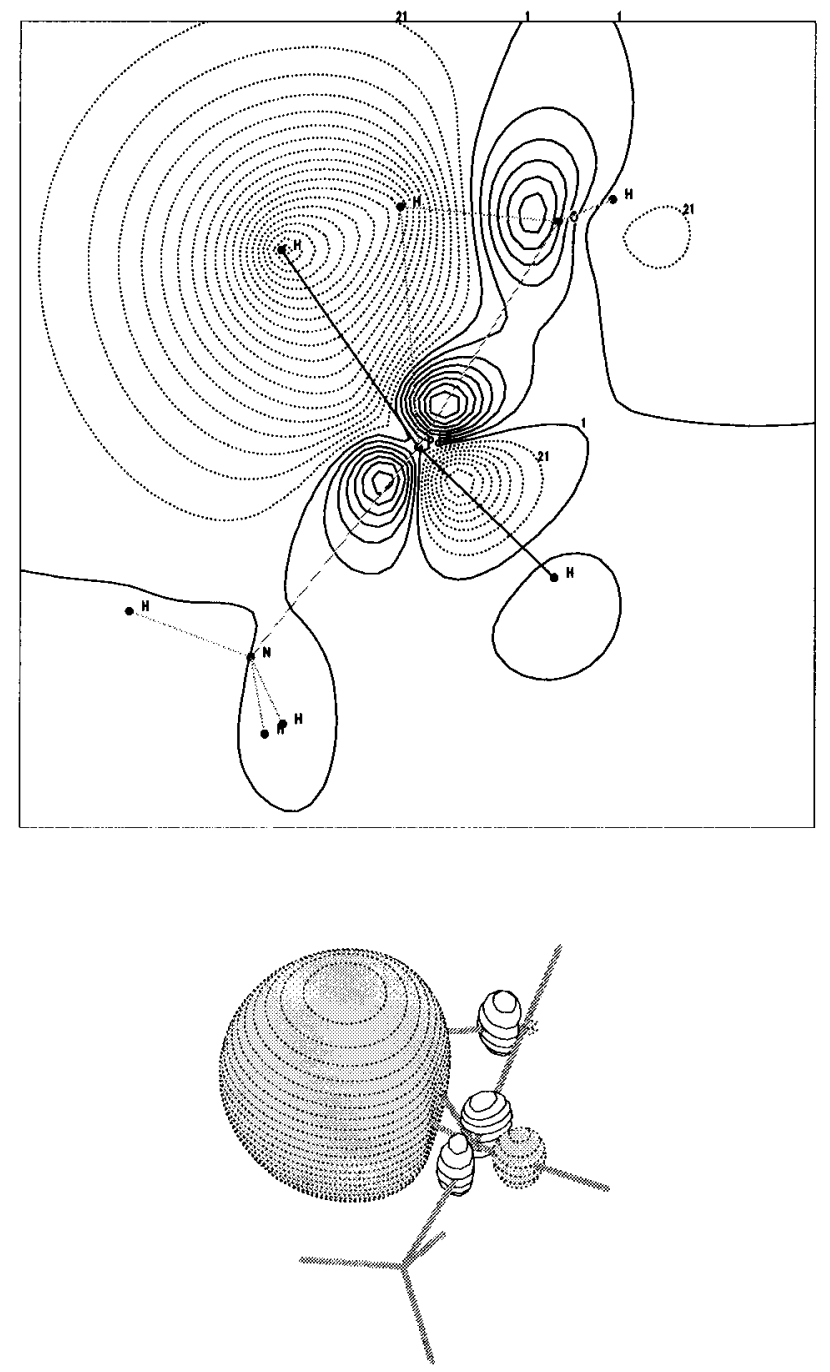

Figure 6. Three-dimensional (below) and in-plane (top) plots $^{33}$ of the contours of the electron density for the HOMO of TS1. The plane shown on top is the molecular plane.

1 and 5 or reactions 2 and 6 , although those for the $\mathrm{d}^{6}$ systems are slightly greater. The analysis of the wave functions also indicates that orbital interactions similar to the ones that we analyzed previously are at work. One finds, for instance, in TS5 an orbital consisting of the bonding combination between $\left[\mathrm{s}_{\mathrm{H}}+\mathrm{d}_{x^{2}-y^{2}}\right.$ ] and $\sigma^{*} \mathrm{H}_{2} \mathrm{O}$ and somewhat destabilized by the $\sigma$ lone pair of $\mathrm{H}_{2} \mathrm{O}$. This orbital is very similar to the HOMO of TS1; compare Figures 8 and 6. Moreover, and as in the subHOMO of TS1, the $\mathrm{p}$ lone pair of $\mathrm{H}_{2} \mathrm{O}$ interacts positively with the empty $\mathrm{Pd} \mathrm{d}_{\sigma}$ orbital to stabilize the transition state; compare Figures 9 and 7 . In this respect, it is interesting to note the proton transfer mechanism between $\operatorname{Ir}\left(\mathrm{D}_{2} \mathrm{O}\right)$ and $\mathrm{Ir}-\mathrm{H}$ sites proposed to account for $\mathrm{H} / \mathrm{D}$ exchange in $\left[\operatorname{IrH}\left(\mathrm{D}_{2} \mathrm{O}\right)(\mathrm{bq}) \mathrm{L}_{2}\right]^{+}$ (bq $=7,8$-benzoquinolinate; $\left.\mathrm{L}=\mathrm{PPh}_{3}, \mathrm{PCy}_{3}\right){ }^{7}$ It occurs in a $\mathrm{d}^{6}$ hexacoordinated system and could well be a $\sigma$-bond metathesis process.

The reader may have noticed that the $\sigma$-bond metathesis reactions that we have analyzed here take place within a $\mathrm{d}^{8}$ square planar or a $\mathrm{d}^{6}$ octahedral coordination sphere, thus implying prior dissociation of a ligand to allow for the coordination of the incoming group or at least its interaction with the metal. We tried to locate a four-center transition state corresponding to the $[2+2]$ reaction of the $\mathrm{O}-\mathrm{H}$ bond of $\mathrm{H}_{2} \mathrm{O}$ with a $\mathrm{Pd}-\mathrm{H}$ bond of the four-coordinate $\mathrm{Pd}(\mathrm{H})_{2}\left(\mathrm{NH}_{3}\right)_{2}$ system, but all our attempts to date have been unsuccessful. ${ }^{38}$ This is not surprising if one remembers how the presence of an empty 

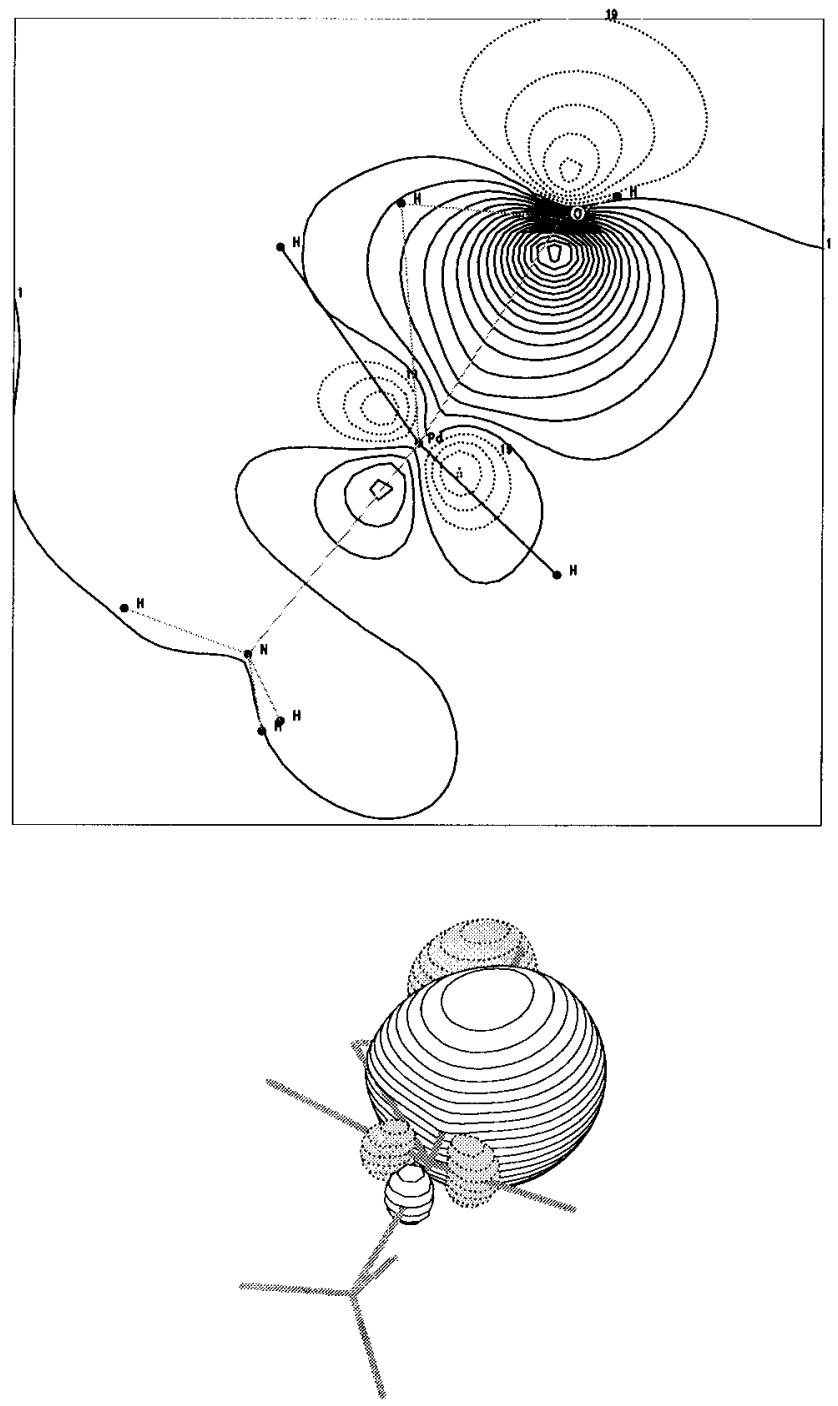

Figure 7. Three-dimensional (below) and in-plane (top) plots ${ }^{33}$ of the contours of the electron density for the sub-HOMO of TS1. The plane shown on top is the molecular plane.

orbital pointing toward the incoming group, such as in $\mathbf{1 7 a}$, is crucial to the interaction with the orbital describing the $\mathrm{O}-\mathrm{H}$ $\sigma$ bond and with the p lone pair of water. An orbital of this type is missing in the $\mathrm{d}^{8}$ square planar palladium system, since the LUMO is directed toward the four ligands. In this context, it is worth mentioning here that the reaction of [Pd$\left.(\mathrm{Me})_{2}(\mathrm{~N} \sim \mathrm{N})\right](\mathrm{N} \sim \mathrm{N}=$ tmeda, bpy) with alcohols to yield a methylpalladium(II) alkoxide complex and $\mathrm{CH}_{4}$ has proved successful for quite acidic alcohols but not for methanol. ${ }^{10}$ The computed barrier for reaction 8 where the two N-ligands are cis, as in the experimental complex, is relatively high, $24.6 \mathrm{kcal}$ $\mathrm{mol}^{-1}$. Dissociation of one arm of the bidendate ligand should be relatively easy, since it lies trans to a methyl ligand. Thus the rate-limiting step might be the metathesis reaction. One would observe a reverse situation in the case of a complex with trans amine ligands. In this case, the dissociation of the amine that is trans to another amine would be more difficult. On the other hand, the $\sigma$-bond metathesis reaction should be easier, since the computed barrier for reaction 7 is $11.9 \mathrm{kcal} \mathrm{mol}^{-1}$ only.

(38) The transition state searches led to a second-order transition state (i.e., with two imaginary frequencies involving the $\mathrm{Pd} \cdots \mathrm{H} \cdots \mathrm{H} \cdots \mathrm{O}$ moiety). In one instance, the search was apparently converging to a six-center transition state in which $\mathrm{H}_{2} \mathrm{O}$ is a relay for the transfer of one hydrogen of the amine ligand to the hydride.


Figure 8. Three-dimensional (below) and in-plane (top) plots ${ }^{33}$ of the contours of the electron density for the orbital of TS5 corresponding to the $\left[\mathrm{s}_{\mathrm{H}}+\mathrm{d}_{\left.x^{2}-y^{2}\right]}\right]+\sigma^{*}{ }_{\mathrm{H}_{2} \mathrm{O}}$ bonding combination. The plane shown on top is the molecular plane.

\section{Summary and Concluding Remarks}

It seems clear from this study that $\sigma$-bond metathesis reactions of water and alcohols with palladium hydride and methyl complexes are feasible pathways (at least in the gas phase), a key factor being the presence of an additional lone pair not engaged in the initial bonding of the metal atom with the reacting water or alcohol. This lone pair allows a continuous rehybrization of the orbitals in the reacting entity and so contributes to the lowering of the energy of the transition state. One has, in fact, a situation that is analogous to the one described for early transition metals. ${ }^{3}$ There, mutual mixing of suitable empty s, p, and d orbitals on the metal maintains the optimal overlap with the adjacent occupied ligand orbital. In the present case, the mixing of the occupied $\mathrm{s}$ and $\mathrm{p}$ lone pairs on the ligand maintains the optimal overlap with the empty $\mathrm{d}_{\sigma}$ metal orbital. The present results show that another and important controlling factor is the respective charges of the reacting entities and, in particular, the polarity of the $\mathrm{Pd}$-hydride or the $\mathrm{Pd}-$ methyl bonds. Interestingly, the presence of strong electronegative ancillary ligands and/or a cis disposition of either two hydrides or two methyl ligands is not a favorable situation. When fourcoordinate square planar $\mathrm{d}^{8}$ palladium alkyl or metal hydride complexes are involved, prior dissociation of a ligand followed by coordination of water or alcohol to the metal seems necessary 

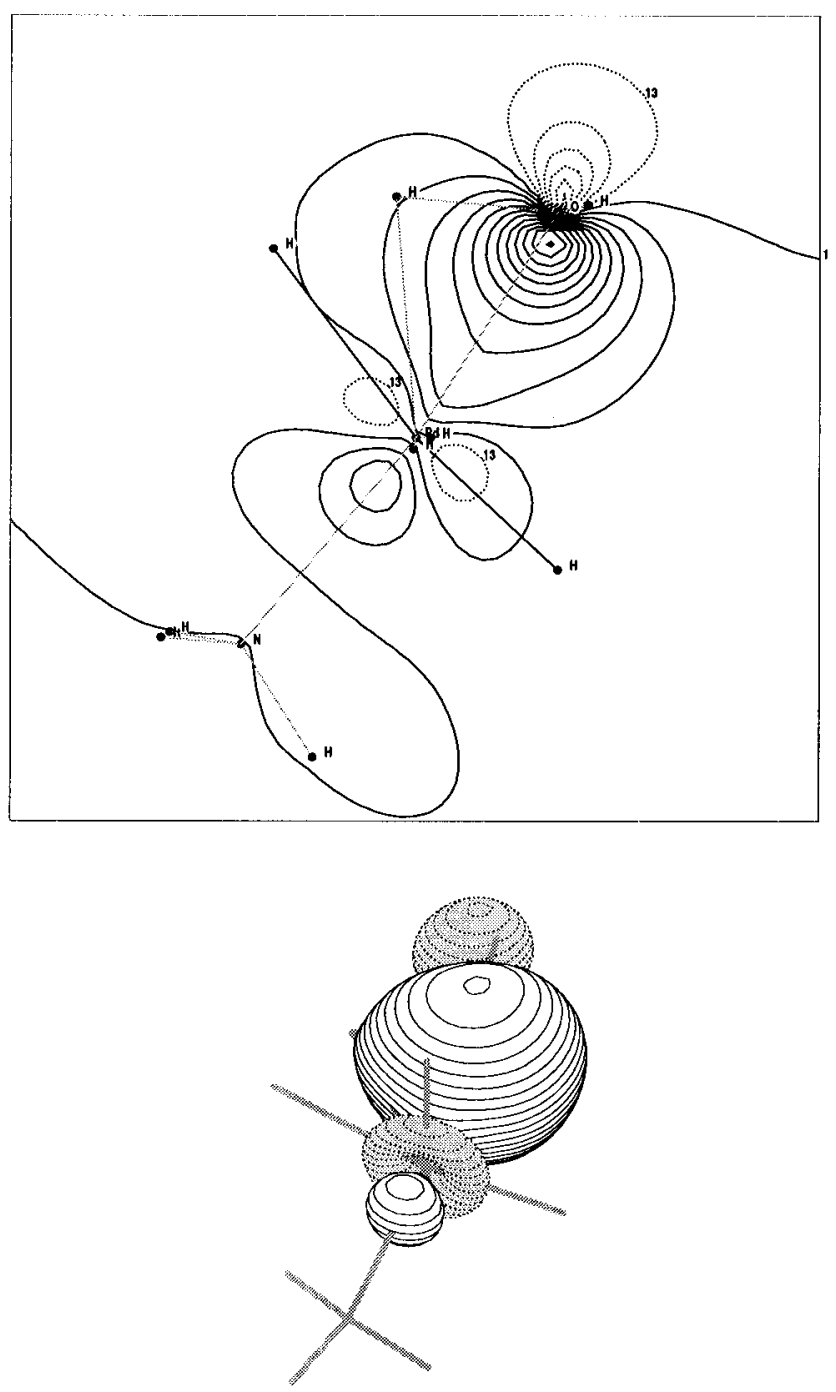

Figure 9. Three-dimensional (below) and in-plane (top) plots ${ }^{33}$ of the contours of the electron density for the orbital of TS5 corresponding to the bonding combination between the $\mathrm{Pd} \mathrm{d}_{\sigma}$ orbital and the $\mathrm{p}$ lone pair of $\mathrm{H}_{2} \mathrm{O}$. The plane shown on top is the molecular plane.

in order to have a genuine $\sigma$-bond metathesis mechanism operative (other mechanisms, e.g. a mechanism involving prior protonation, may be operative if there is no dissociation). This dissociation yields the empty $\mathrm{d}_{\sigma}$ orbital, which accounts for the allowance of the $\left[2_{\mathrm{s}}+2_{\mathrm{s}}\right]$ process. Note that the situation may be different in the case of platinum systems, where lowlying $\mathrm{p}$ or s empty orbitals are available on the metal center. Alkoxide-alcohol exchange reactions between an alcohol and a metal alkoxide complex may also operate via a different mechanism. ${ }^{10-13}$

Another competitive pathway that should not be overlooked in dealing with $\sigma$-bond metathesis reactions in late transition metal chemistry is a sequence of oxidative additions and reductive eliminations. It is known that the oxidation state IV of palladium is a generally unfavorable oxidation state. But $\mathrm{Pt}(\mathrm{II})$ or $\operatorname{Ir}(\mathrm{I})$ systems may behave differently. For instance, in their study of the mechanism of the Shilov reaction (the activation of alkane $\mathrm{C}-\mathrm{H}$ bonds by $\mathrm{Pt}(\mathrm{II})$ salts), Siegbahn and Crabtree found the oxidative addition/reductive elimination sequence competitive with the $\sigma$-bond metathesis pathway. ${ }^{5 \mathrm{c}}$ Also the methane metathesis process at the $\left[\mathrm{Cp} * \operatorname{Ir}\left(\mathrm{P}_{\left.\left(\mathrm{CH}_{3}\right)_{3}\right)-}\right.\right.$ $\left.\left(\mathrm{CH}_{3}\right)\right]^{+}$system observed experimentally by Bergman et al. ${ }^{39}$ seems to involve, according to the recent theoretical study of

(39) Arndtsen, B. A.; Bergman, R. G. Science 1995, 270, 1970.



Figure 10. Energy diagrams for the model reaction of $\mathrm{H}_{2} \mathrm{O}$ with trans$\left[\mathrm{Pd}(\mathrm{H})_{2}(\mathrm{NH} 3)_{2}\right]$ (top) and cis-[ $\left.\mathrm{Pd}(\mathrm{H})_{2}\left(\mathrm{NH}_{3}\right)_{2}\right]$ (bottom) proceeding through either a $\sigma$-bond metathesis mechanism (right) or an oxidative addition/reductive elimination mechanism (left).

Hall et al., ${ }^{40}$ a two-step oxidative addition/reductive elimination mechanism rather than a genuine $\sigma$-bond metathesis process. One should note, however, that in this case an extra $\mathrm{p}$ lone pair cannot be involved. A comprehensive comparison of the two alternatives ( $\sigma$-bond metathesis vs two-step oxidative addition/ reduction elimination) for reactions $1-8$ lies beyond the scope of the present study. We have nevertheless made this comparison in two prototypic cases, viz. for the model reactions of $\mathrm{H}_{2} \mathrm{O}$ with trans- and cis- $\left[\mathrm{Pd}(\mathrm{H})_{2}\left(\mathrm{NH}_{3}\right)_{2}\right]$. The two corresponding energy diagrams are shown in Figure 10. It is clear from these diagrams that when the $\sigma$-bond metathesis mechanism is favored, the oxidative addition/reductive elimination mechanism is not favored and vice versa: In the reaction with the trans$\left[\mathrm{Pd}(\mathrm{H})_{2}\left(\mathrm{NH}_{3}\right)_{2}\right]$ system, the oxidative addition has a barrier of $42.0 \mathrm{kcal} \mathrm{mol}{ }^{-1}$ whereas the energy barrier for the $\sigma$-bond metathesis of $\mathrm{H}_{2} \mathrm{O}$ is $12.6 \mathrm{kcal} \mathrm{mol}^{-1}$ only. Although one should add to this value the cost of the substitution of $\mathrm{NH}_{3}$ by $\mathrm{H}_{2} \mathrm{O}$, the $\sigma$-bond metathesis pathway remains competitive. ${ }^{41}$ The high barrier of the oxidative addition is in fact linked to the strong endothermicity, which in turn is traced to the mer conformation

(40) Strout, D. L.; Zaric, Z.; Niu, S.; Hall, M. B. J. Am. Chem. Soc. 1996, $118,6068$. 
of the trihydrido $\mathrm{Pd}(\mathrm{IV})$ product. ${ }^{43}$ On the other hand, for the cis- $\left[\mathrm{Pd}(\mathrm{H})_{2}(\mathrm{NH} 3)_{2}\right]$ system, the energy barrier for the oxidative addition is $28.9 \mathrm{kcal} \mathrm{mol}^{-1}$, lower than the energy barrier for the $\sigma$-bond metathesis, $37.4 \mathrm{kcal} \mathrm{mol}^{-1}$.

Finally, one may be concerned about the relevance of these gas phase calculations to reactions taking place in solution. The dielectric constants of the solvents typically used in the experiments (diethyl ether, ${ }^{8 \mathrm{a}, 10}$ toluene, ${ }^{8 \mathrm{c}, 9}$ benzene, ${ }^{10}$ and dichloromethane ${ }^{7,10}$ ) are quite low, however. Thus the gas phase calculations should provide a rather realistic picture of the process. In order to estimate the long-range dielectric effects of the solvent, the Onsager model was used and SCRF (selfconsistent reaction field) calculations were carried out at the MP2 level for reaction 7 with $\mathrm{Et}_{2} \mathrm{O}$ as a solvent, yielding an energy barrier of $11.6 \mathrm{kcal} \mathrm{mol}^{-1}$, i.e. a decrease of $0.3 \mathrm{kcal}$ mol $^{-1}$ only. ${ }^{44,45}$

Note Added in Proof. A very recent article by Musaev et al. also reports, on the basis of DFT B3LYP calculations, a low-energy pathway for the $\sigma$-bond metathesis reaction in $\left[\mathrm{L}_{2} \mathrm{Pd}(\mathrm{RH})\left(\mathrm{H}_{2}\right)\right]^{+}\left(\mathrm{L}_{2}=\mathrm{HN}=\mathrm{C}(\mathrm{H}) \mathrm{C}(\mathrm{H})=\mathrm{NH}, \mathrm{R}=\mathrm{CH}_{3}, \mathrm{C}_{2} \mathrm{H}_{5}\right.$, $\left.\mathrm{C}_{3} \mathrm{H}_{7}\right) \mathrm{Pd}(\mathrm{II})$ diimine complexes. ${ }^{46}$ Since the energy of $\mathbf{1 7 a}$ is most likely quite low in these positively charged systems, we

(41) The substitution of $\mathrm{H}_{2} \mathrm{O}$ by $\mathrm{NH}_{3}$ is computed to be endothermic by $16.2 \mathrm{kcal} \mathrm{mol}^{-1}$. We have not investigated whether it involves a dissociative or an associative pathway. On the basis of our previous results for the substitution of $\mathrm{NH}_{3}$ by $\mathrm{CO},{ }^{42}$ one may expect the associative pathway to be favored with an energy barrier of a few kilocalories per mole.

(42) Markies, B. A.; Wijkens, P.; Dedieu, A.; Boersma, J.; Spek, A. L.; van Koten, G. Organometallics 1995, 14, 5628. expect the interaction 18a to be much stronger in these cationic complexes than in our neutral systems, thus leading to low energy barriers.

Acknowledgment. Calculations were carried out on the IBM RS 6000 workstations of our laboratory at the Institut du Developpement et de Ressources en Informatique Scientifique (IDRIS, Orsay, France) and on the DEC 3000/600S workstations at the Centre Universitaire Régional de Ressources Informatiques (CURRI, Strasbourg, France). A.D. and A.M. are grateful to Dr. L. Padel and Mrs. Fersing for their technical assistance. The stay of G.K. in Strasbourg was supported in part by the Netherland Foundation for Chemical Research (SON) with financial aid from the Netherland Organization for Scientific Research (NWO).

IC960807L

(43) This feature is quite general and has been found for other oxidative addition reactions involving $\mathrm{Pd}(\mathrm{II}) / \mathrm{Pd}(\mathrm{IV})$ oxidation states: Milet, A.; Dedieu, A. Unpublished results.

(44) The SCRF calculations were carried out at the MP2 level, using the gas phase optimized MP2 geometries and taking into account dipole and quadrupole types of interactions. The dielectric constant of diethyl ether was taken to be 4.3 . The cavity radii were obtained following the standard procedure of the Gaussian 94 program (i.e., by determining the volume inside a contour of $0.001 \mathrm{e}^{-\mathrm{bohr}^{3}}$ density and then augmenting the radius corresponding to this volume by $0.5 \AA$ ).

(45) The energy difference between TS7 and $\mathbf{1 5}$ was also hardly changed, from -33.0 to $-33.7 \mathrm{kcal} \mathrm{mol}^{-1}$.

(46) Musaev, D. G.; Svensson, M.; Morokuma, K.; Strömberg, S.; Zetterberg, K.; Siegbahn, P. E. M. Organometallics 1997, 16, 1933. 